\title{
Transcatheter valve-in-valve implantation vs. reoperative mitral valve surgery for failing surgical prosthesis
}

\author{
Francesco Nappi ${ }^{1}$, Emanuele Verghi ${ }^{2}$, Sanjeet Singh Avtaar Singh ${ }^{3}$, Antonio Nenna ${ }^{2}$, Pierluigi Nappi ${ }^{4}$, \\ Camilla Chello², Massimo Chello ${ }^{2}$
}

\begin{abstract}
1 Department of Cardiac Surgery, Centre Cardiologique du Nord de Saint-Denis, Paris 93200, France. ${ }^{2}$ Department of Cardiovascular Surgery, Università Campus Bio-Medico di Roma, Rome 00128, Italy. ${ }^{3}$ Department of Cardiothoracic Surgery, Golden Jubilee National Hospital, Glasgow G1 2FF, UK.

${ }^{4}$ Department of Clinical and Experimental Medicine, University of Messina, Messina 98121, Italy.
\end{abstract}

Correspondence to: Prof. Francesco Nappi, MD, Cardiac Surgery, Centre Cardiologique du Nord de Saint-Denis, 36 Rue des Moulins Gémeaux, Saint-Denis 93200, France. E-mail: francesconappi2@gmail.com

\begin{abstract}
How to cite this article: Nappi F, Verghi E, Singh SSA, Nenna A, Nappi P, Chello C, Chello M. Transcatheter valve-in-valve implantation vs. reoperative mitral valve surgery for failing surgical prosthesis. Vessel Plus 2021;5:40.

https://dx.doi.org/10.20517/2574-1209.2021.06
\end{abstract}

Received: 12 Jan 2021 First Revised: 9 Feb 2021 Revised: 13 Feb 2021 Accepted: 9 Mar 2021 Published: 19 Jul 2021

Academic Editor: Manel Sabate Copy Editor: Xi-Jun Chen Production Editor: Xi-Jun Chen

\begin{abstract}
The incidence of degenerated mitral bioprosthesis is increasing in clinical practice due to a greater use of biological prostheses for mitral valve replacement compared to mechanical valves and increased life expectancy after cardiac surgery. Similarly, mitral valve repair can result in long-term recurrence of mitral valve disease requiring reintervention. Therefore, the number of failing surgical prosthesis or repaired valves will increase over the next years representing a new challenge in the corrective approach in the case of long-term structural valve degeneration. Those patients were generally managed with reoperative mitral valve surgery, but transcatheter interventional therapies, initially considered an option in patients who are ineligible for redo surgery, have been recently associated with excellent outcomes. The efficacy and safety of transcatheter mitral valve procedures have been reported in both failing ring annuloplasty or degenerated mitral bioprosthesis, but the use of non-dedicated devices remains associated with significant severe complications such as device malpositioning or left ventricular outflow tract obstruction requiring emergent conversion to open surgery. Both the careful selection of patients and pre/intra-procedural scheduling are warranted to maximize benefits and reduce issues. This review focuses on emerging transcatheter mitral valve replacement devices as therapeutic options for degenerated mitral bioprosthesis or failed mitral repair. This paper aims to summarize current interventional techniques and available evidence, comparing outcomes between transcatheter technologies and reoperative mitral valve surgery.
\end{abstract}

The Author(s) 2021. Open Access This article is licensed under a Creative Commons Attribution 4.0 International License (https://creativecommons.org/licenses/by/4.0/), which permits unrestricted use, sharing, adaptation, distribution and reproduction in any medium or format, for any purpose, even commercially, as long as you give appropriate credit to the original author(s) and the source, provide a link to the Creative Commons license, and indicate if changes were made.

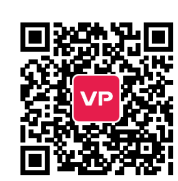


Keywords: Mitral valve, regurgitation, ischemic mitral, transcatheter, replacement, repair

\section{INTRODUCTION}

The increase in the number of mitral valve repair operations, with a rise in the number of biological prostheses implanted in younger patients, has resulted in higher incidences of reoperative mitral valve surgery. Bioprosthesis replacement for deterioration or failed repairs and mitral annular calcification (MAC) pose ongoing challenges to the surgical management of patients requiring repeat valve surgery (Re$\mathrm{MVS})^{[1-4]}$.

There is currently evidence that the percentage of structural valvular degeneration (SVD) is $85 \%$ in patients after previous MV surgery ${ }^{[1]}$. In these cases, a second mitral valve surgery may be required in $35 \%$ of cases within the first 10 years $^{[5,6]}$. For patients who have undergone primary mitral valve surgery, the greatest concern falls on the best choice for the subsequent surgical therapeutic approach. The crossroads is therefore represented between the choice of mitral valve reoperation using a standard surgical approach or, alternatively, the transcatheter mitral valve implantation procedure. In addition, given the high risk and prohibitive operative mortality for reoperation after mitral valve replacement operation (Re-MVRpl) or mitral valve repair procedure (Re-MVRp), the search for an alternative to the standard surgical approach is both judicious and desirable.

The literature has reported successful cases of transmitral valve-in-valve replacement (TMViVR) in nonsurgical candidates in whom a mitral valve bioprosthesis or surgical repair failed ${ }^{[7]}$.

The consolidated experience gained with the Sapien Transcatheter Heart Valve (Edwards Life Sciences, Irvine CA) has led to accelerate legislative endorsement by the United States Food and Drug Administration (FDA) which has authorized the use of transcatheter valve treatment (TVT) for the treatment of the diseased mitral valve ${ }^{[8-11]}$.

As a result, it was possible to extend the indication for the use of these devices to Medicare and Medicaid Services (CMS) patients. The well-defined role of NCD has left the heart team to create a nationally verified prospective registry for each hospital.

Patients in whom therapy [transcatheter mitral valve-in-valve therapies (TMViV-T)] is recommended are closely surveilled as part of the after-market monitoring and followed up to assess the quality of the results produced at the individual level by the centers involved in TMViV-T.

The TMViV/TMViR module is one of three modules of the National Registry, the others being transcatheter aortic valve replacement (TAVR). Instead, patients who are managed with transcatheter aortic valve-in-valve are included in the TAVR module. The TMViV-T module gathers patients' demographic information and comorbidities. In addition, the TMViV/TMViR registry contains specific baseline criteria to characterize mitral valve disease, reporting detailed notes on the procedure adopted as well as the results on mortality and morbidity. Specifically, it reports mortality to 30 days and 1 year and provides information on hospital admissions and quality of life. A risk model for the prediction of hospital mortality is also listed in the United States National Registry which references the TMViV/TMViR module. It is useful to compare the results reported both with national averages and with those obtained from peer groups, with the aim to improve and refine the quality of the procedure. Mechanical intervention with the transcatheter approach for structural degeneration of the mitral valve prosthesis or failure of MV repair can be performed using the 
TMViV or the TMViR technique ${ }^{[12-19]}$. This type of approach can be considered a safe alternative to reduce the risk of operative mortality and increase the clinical benefit in patients experiencing heart failure $(\mathrm{HF})^{[12]}$.

Reoperation for previous mitral repair failure or prosthesis degeneration can be performed via a second sternotomy or through a right thoracotomy approach ${ }^{[20-22]}$. The intraoperative risk assessment of a resternotomy is evaluated by thoracic CT and coronary or graft catheterization. Cardiopulmonary bypass (CPB) will be established using the femoral vessels and the sternum will be reopened using an oscillating saw. The right thoracotomy instead will be performed by making an incision on the right infra-mammary fold, isolating the right lung and opening the pericardium anterior to the right phrenic nerve, which will be isolated and protected so as to allow safe surgical access to the left atrium ${ }^{[0,23-25]}$.

Despite the lack of established guidelines to choose the safest therapeutic approach and the presence of established evidence related to surgical approaches, the recent feasibility results for transcatheter mitral valve-in-valve procedures place the treatment of structural heart disease into a novel prospective with evidence ${ }^{[13-16]}$.

We undertake this review with the primary goal to reassume the existing evidence for the use of transcatheter mitral valve procedures or when repeat reoperative mitral valve surgery is required. We focus on the recent results from prospective registry studies, propensity matched observational series, metaanalyses and unmatched observational series. Our secondary objective is to identify a pool of patients for whom the benefits of the transcatheter mitral valve (TMViV) and ring valve (TMViR) procedure are more evident than standard redo surgical therapy ${ }^{[5-7,12,13]}$.

With the aim to encourage a broader use of transcatheter mitral valve-in-valve implantation and provide drive for health professionals, we herein argue the current evidence for the choice of the various transcatheter mitral valve-in-valve therapies (TMViV-T). Finally, we develop a useful evidence-based algorithm to guide the choice of the mitral valve prosthesis in case of reoperation.

\section{The emerging new contribution of transcatheter mitral valve-in-valve therapy}

TMViV-T is presently considered in the United States and Europe for the management of deteriorated MV (TMViV) or mitral ring (TMViR) prostheses in patients at high risk for standard surgical approach ${ }^{[17,18]}$.

Unlike Mitraclip therapy, in which the legislative endorsement is based on the results reported from the Endovascular Valve Edge-to-Edge Repair randomized Study (EVEREST) ${ }^{[19]}$, there is poor evidence on the survival benefit in patients who have undergone TMViV/TMViR for deteriorated bioprostheses compared to those who had redo surgery for SVD of $\mathrm{MV}^{[3,14,15,17,19]}$.

Both procedures had the same enrollment method for the patients who were considered suitable for the use of devices, therefore 349 persons from 98 sites were included in the US registry from 2013 to $2015^{[26]}$. Nevertheless, the recent literature shows that the transcatheter procedure with the use of Mitraclip has a slight advantage over TMViV-T due to a better understanding of the pathophysiology of mitral rigurgitation and the normalization of the geometry ${ }^{[2-4,8,9,27-30]}$.

Recipients of transcatheter mitral valve implant $(n=248)$ were treated for degenerated mitral valve prosthesis (TMViV 76.1\%) or severe mitral regurgitation occurring after a mitral valve repair using annular ring (TMViR 23.9\%). The population recruited in the TMViV-T group was at high risk for conventional open mitral valve operation, with a median age of 76 years and being predominantly female $(61 \%)^{[18,26]}$. 
TMViV-T includes a transapical, transatrial or transseptal approach. The transapical approach is performed by practicing a small anterolateral thoracotomy in the fifth or sixth intercostal space which is used to access the pericardial space near the left ventricular apex. At this level, the transcatheter heart valve (THV) delivery system is introduced. The advantage of this approach is due to the anatomical peculiarity that allows direct access to the entire mitral apparatus aimed at the coaxial retrograde deployment of the transcatheter heart valve in patients presenting with a failed surgical mitral bioprosthesis. Instead, the transatrial approach technique is performed through a small anterolateral thoracotomy which allows the antegrade deployment of the transcatheter heart valve device. Finally, the transseptal approach is achieved with an initial access through the femoral vein, which allows the catheters and delivery system to progressively advance towards the left atrium. A transseptal puncture is performed, allowing for the deployment of the antegrade transcatheter heart valve $\mathrm{e}^{[18,26]}$.

The main advantage of the transseptal approach is avoiding a thoracic incision, which offers a quick postprocedural recovery after mechanical intervention. Moreover, its indication is suitable in patients with severe chronic lung disease or in those who were managed with multiple sternotomies ${ }^{[8,18,26,28]}$.

The preferred approach was the transapical access (70.1\%) over transseptal (24.4\%). It is important to note that in-hospital and 30-day mortality was much less common than their STS PROM (8.5\% vs. 11\%), while $1.4 \%$ of patients experienced postoperative left ventricular outflow tract obstruction. In addition, considering the fragility of patients treated with this type of mechanical intervention, the post-procedure morbidity was low. A postoperative left ventricular outflow tract obstruction occurred in very few patients; similarly, the rate of stroke or need for dialysis was low in recipients of TMViV-T. Repeat mitral valve surgery during hospitalization was not required for any patient. Considering that $83.7 \%$ of the patients had echocardiographic control available, moderate to severe mitral regurgitation occurred infrequently and the measured transvalvular mitral gradients were low. Evidence based on early outcomes in this group of highrisk patients, for whom repeat open mitral valve surgery was avoided, is encouraging. Therefore, TMViV-T can be offered as an effective treatment option for this category of patients ${ }^{[18,26-28]}$.

\section{Clinical evidence and technical evolution using transcatheter mitral valve-in-valve therapy}

The international registry for transcatheter mitral valve replacement (TMVR) was established with the aim to treat patients with degenerated mitral bioprostheses and failed annuloplasty rings who are suitable to receive the transcatheter mitral valve-in-valve therapy. All patients who were subsequently recruited, with a mean age of 72.5 years and a mean STS score of $8.9 \% \pm 6.8 \%$ [Table 1], constitute the TMVR registry, which serves as a multicenter observational study. It was due in November 2015 with a total of 25 centers from Europe and North America working to implement and improve the registry. In total, 248 patients were included to receive a mechanical intervention on the mitral valve through transcatheter-based therapy. Of these, 176 patients $(71 \%)$ were considered to receive a TMViV for a degenerated mitral bioprosthetic valve, whereas 72 patients $(29 \%)$ had TMViR due to failed annuloplasty rings ${ }^{[8,19,27,29,30]}$.

Considering the cohort, we noted a relatively low rate of procedure-related death $(n=3 ; 1.2 \%)$, conversion to conventional surgery $(n=5 ; 2 \%)$, valvular embolization $(n=4 ; 1.6 \%)$ and left ventricular perforation occurred $(n=1 ; 0.4 \%)$. Across the group, left ventricular outflow obstruction occurred in $8(2.3 \%)$ patients, but there was no difference between patients receiving TMViV $(4 ; 2.3 \%)$ or those undergoing TMViR (4; $2.3 \%$ ). Patient-related successful procedure was achieved in $92.3 \%$ of device recipients; however, a significantly lower technical success rate was noted in patients who were managed with TMViR than in those who had TMViV. Other significant differences included reintervention for paravalvular leak that occurred more frequently in patients who were managed with TMViR compared to those who underwent 
Table 1. Baseline characteristics of all patients in transcatheter approach group ${ }^{[1,15,23,24,26,31]}$

\begin{tabular}{|c|c|c|c|c|c|c|c|c|}
\hline & Overall & TMViV & TMViR & TMVIMAC & $\begin{array}{l}\text { Age, } y, \\
\text { median }\end{array}$ & $\begin{array}{l}\text { STS } \\
\text { score }\end{array}$ & $\begin{array}{l}\text { NYHA Class } \\
\text { III or IV }\end{array}$ & $\begin{array}{l}\text { LVEF (\%; mean } \pm \\
\text { SD) }\end{array}$ \\
\hline US Registry & 349 & 266 & 83 & & 76 & 11.1 & & \\
\hline \multirow[t]{2}{*}{ Brigham and Women's Hospital } & 520 & $\begin{array}{l}\text { prev } \\
\text { MVR }\end{array}$ & $\begin{array}{l}\text { prev } \\
\text { MVP }\end{array}$ & & $63.3 \pm 13.5$ & $\begin{array}{l}6.12 \pm \\
6.52\end{array}$ & 319 & 60 \\
\hline & & 273 & 247 & & & & & \\
\hline TMVR Registry & 248 & 176 & 72 & & $72.5 \pm 12.1$ & $8.9 \pm 6.8$ & 221 & $52.5 \pm 13.9$ \\
\hline $\begin{array}{l}\text { Mayo Clinic, NY University Medical Centre, Intermounitain Heart Institute, University of } \\
\text { Alabama, St. Michael's Hospital, Centre Cardiologique du Nord }\end{array}$ & 87 & 60 & 15 & 12 & $75 \pm 11$ & $13 \pm 8$ & 87 & $57 \pm 11$ \\
\hline Multicentre Published reports (2009-2018) & 245 & 172 & 73 & & $73 \pm 12.1$ & $\begin{array}{l}15.6 \pm \\
13.5\end{array}$ & 98.2 & $46.7 \pm 14.1$ \\
\hline Flinders Medical Centre (Adelaide) (2017-2018) & 7 & 7 & & & 82 & 4.34 & 5 & $\begin{array}{l}>60 \%(5) ; 30 \%- \\
45 \%(2)\end{array}$ \\
\hline St. Paul's Hospital (Vancouver, Canada) & 23 & 23 & & & $81.1 \pm 5.8$ & $\begin{array}{l}12.6 \pm \\
6.9\end{array}$ & 22 & $54.5 \pm 12.3$ \\
\hline
\end{tabular}

TMViV: Transcatheter mitral valve-in-valve; TMViR: transcatheter mitral valve-in-ring; STS: Society of Thoracic Surgeons; NYHA: New York Heart Association; LVEF: left ventricle ejection fraction; TMVR: transcatheter mitral valve replacement; TMVIMAC: transchateter mitral valve in mitral annular calcification; MVR: mitral valve repair; MVP: mitral valve replacement.

TMViV (6.9\% vs. 2.3\%; $P=0.07)$, respectively. The concern related to life-threatening or fatal bleeding more frequently affected TMViR recipients ( $8.3 \%$ TMViR vs. 2.3\% TMViV; $P=0.03)$, while reoperation was necessary for 25 patients $(10.1 \%)$, more frequently in the TMViR arm than in the TMViV one $(16.7 \% \text { vs. } 7.4 \% ; P=0.03)^{[18,26]}$.

The survival benefits of TMViV-T in a small number of patients with failed bioprosthetic mitral valves were proved in a report by Nappi et al. ${ }^{[32]}$ and Webb et al. ${ }^{[33]}$ nearly 10 years ago. TMViV-T was used for 24 high-risk patients with degenerated valves bioprostheses (aortic, $n=10$; mitral, $n=7$; pulmonary, $n=6$; or tricuspid, $n=1$ ). The first-in-human use of a percutaneous transseptal approach was unsuccessful. On the contrary, five subsequent patients were managed successfully with the use of transapical access for TMViV implantations. The procedure was relatively easily accomplished; all patients not only survived at 30-day follow-up, but there was no mortality at a median 72 -day follow-up ${ }^{[16,18,1,1,28]}$.

TMViR has been used since 2010 in a restricted number of patients $(n=17)$ who had failed annuloplasty rings, demonstrating how promising this safe and efficacious approach is for this type of mechanical intervention. The survival rate survival was $82 \%$ (14/17 patients) at 30 days, while, at the most recent followup (13 \pm 5 months), the percentage of surviving patients dropped to $71 \%(12 / 17)^{[34]}$. 
Two years later, Elmariah et al. ${ }^{[10]}$, using fluoroscopic and echocardiographic guidance, described the successful implantation of TMViV through the left ventricular apex. The authors implanted a $26-\mathrm{mm}$ Edwards SAPIEN heart valve (Edwards Lifesciences) that was accurately placed within the previous stenosed mitral 27-mm bioprosthesis Carpentier Edwards Perimount (Edwards Lifesciences, Irvine, California). Surgery with a conventional standard approach was not recommended for the patient because he presented numerous comorbidities including cerebrovascular disease [95\% stenosis of the left internal carotid artery (ICA) and moderate stenosis of the right ICA]. He had undergone a previous coronary artery bypass grafting (CABG)/MVR which was complicated with a dehiscence of the sternal wound requiring complex reconstruction and had received recent percutaneous coronary intervention. Moreover, the patient was managed with bilateral renal artery stenting.

Simultaneously, Seiffert et al. ${ }^{[35]}$ reported the improved outcome using the transapical TMViV implantation in 6 patients. The amelioration of the clinical condition is almost certainly due to rapid improvement in hemodynamics, as testified by the reduction of the mean transvalvular gradients [from $11.3 \pm 5.2 \mathrm{mmHg}$ to $5.5 \pm 3.6 \mathrm{mmHg}(P=0.016)$ ] and median MV regurgitation \{from grade 3.0 [interquartile range (IQR): $2.7-$ 3.1] to o (IQR: 0-1.0); $P=0.033\}$. Patients were checked over a median follow-up of 70 days (IQR: $25.5-358$ days), showing an increased functional status with median NYHA functional class [from 3.0 (IQR: $3.0-3.5$ ) to 2.0 (IQR: 1.5-2.0); $P=0.048$ ]. A different approach from the transapical one, however, remained a primary objective.

A few years later ${ }^{[11]}$, the first 4 consecutive patients successfully received a transcatheter mitral valve replacement for the treatment of degenerated mitral valve bioprostheses that included both bioprosthetic valves $(n=2)$ or rings $(n=2)$ and using the transseptal access. The cornerstone of this report was to highlight how the innovative transcatheter mitral valve replacement technique could be performed using transvenous and transseptal mitral valve replacement. The authors, demonstrating the feasibility of the procedure with only femoral venous approach, stated the reduction of complications and length of hospital stay in TMViV-T recipients compared to those who were managed with transapical access or redo surgery ${ }^{[5,31]}$.

The percutaneous transvenous transseptal approach was reported in one study including 48 high-risk patients with a median follow-up of 40 days (range: 1-491 days) and the mean Society of Thoracic Surgeons (STS) risk score was $13.2 \% \pm 7.4 \%$ with a mean age of $76 \pm 11$ years ${ }^{[14,18,27,28]}$. Patients were managed using an Edwards SAPIEN prosthesis (Edwards Lifesciences, Irvine, California) and received TMViV/R therapy for 33 degenerated mitral bioprostheses, 9 previously failed annuloplasty and 6 severe MAC. Considering the overall group of patients undergoing treatment, it is important to underline that efficacy was achieved in 42 of 48 patients $(88 \%)$. In detail, the success rate was reached for $94 \%$ (31 out of 33 ) of patients who underwent the mechanical intervention for the failed bioprosthetic mitral, whereas it was $73 \%$ (11 out of 15 patients) for those with failed annuloplasty rings and $\mathrm{MAC}^{[14,15]}$.

While awaiting the outcome of large series of multicenter registry studies, there is currently an unremarkable amount of evidence to sustain the use of percutaneous transfemoral antegrade transseptal implantation for mitral prostheses, even though this may provide an encouraging survival benefit over a standard Re-MVS. Indeed, more than 7 years ago, a cohort of 23 patients was studied with a median followup greater than 2 years revealing a Kaplan-Meier survival rate of $90.4 \%^{[9,20,36,37]}$.

Only one independent study has confirmed this finding in a larger cohort and with the use of transseptal balloon-expandable TMViV-T. The study reported the results from 87 patients, of whom approximately 
three-quarters had a degenerated mitral bioprostheses. For patients who underwent TMViR/valve related to MAC disease, the estimated survival rate was $78 \%$ at 30 days. Instead, for those who received TMViV for degenerated bioprosthetic mitral valve, the survival rate was $95 \%$ at 30 days [ $95 \%$ confidence interval (CI): $70 \%-86 \%$ vs. $92 \%-97 \% ; P=0.008$ ]. Finally, the survival rate was $68 \%$ in patients who had transcatheter mitral valve therapy $\mathrm{ViR} / \mathrm{ViV}$ in MAC group compared to the rate of $86 \%$ in those who were managed with transcatheter mitral valve therapy for failed bioprosthetic mitral valve at 1-year follow up (95\%CI: 58\%-78\% vs. $81 \%-91 \% ; P=0.008)^{[1,1,15]}$.

Hu et al. ${ }^{[23]}$, in a recent systematic literature review, analyzed the outcomes of 245 patients who underwent TMVR (172 TMViV and $73 \mathrm{TMViR}$ ) surgery for degenerated bioprostheses and failed annuloplasty ring from 2009 to 2018. The mean age of all candidates for TMViV therapy was $73 \pm 12$ years, with a mean STS score of $15.6 \% \pm 13.5 \%$ and mean LVEF or $46.7 \% \pm 14.1 \%$. In this review, the technical success rate was $93.5 \%$ and the operative mortality was $5.7 \%$ with no significant differences between the two groups (5.2\% TMViV vs. 6.8\% TMViR). In the entire study, left ventricular outflow obstruction were observed in 4 (1.6\%) patients: $0(0 \%)$ in the TMViV group and $4(5.5 \%)$ in the TMViR group.

In a recent review with a 5-year follow up, Cheung et al. ${ }^{[31]}$ reported 23 consecutive patients with degenerated mitral bioprosthesis, who were successfully treated using TMViV. Patients received Edwards SAPIEN-type balloon-expandable valves with a left ventricular apex approach. The success of the device was $100 \%$ and no cases of valve related malposition or embolization occurred ${ }^{[31]}$.

As demonstrated by the reported data and the cited studies, despite the evidence of low intraoperative and postoperative mortality and low incidence of major bleeding and stroke, the main concern with the use of TMViV-T, besides the possible need for a reoperation, is the increased risk of complications from LVOT obstruction and death related to congestive heart failure.

Eleid et al. ${ }^{[14,15]}$ showed that LVOT obstruction significantly increased in patient with higher ejection fractions ( $66 \pm 6 \mathrm{mmHg} v s .56 \pm 12 \mathrm{mmHg} P=0.002$ ). This risk is even higher in TMViR or TMV-in-MAC recipients than in those who had TMViV procedures. It is important to point out that the majority of patients who had minimal symptoms related to LVOT obstruction were managed conservatively, showing transvalvular mitral gradients decreasing over time. Nevertheless, in some cases, patients who received TMViVR or TMV-in-MAC developed a critical obstruction related to displacement of the systolic anterior mitral leaflet in the left ventricular outflow tract resulting in irreversible impairment of cardiac function with death due to the onset of congestive heart failure. However, the incidence of severe LVOT issue and other complications can be notably decreased by careful patient screening ${ }^{[24,33-35]}$.

Another concern is related to the choice of the appropriate size of the implant, which remains a matter of debate. We mainly adopt an oversizing of 5\%-10\% compared to the pre-existing prosthesis. The reference considered is the internal diameter reported by the producer, so, for patients who had a prosthesis with an internal diameter of less than $21.5-\mathrm{mm}$, a $23-\mathrm{mm}$ SAPIEN valve is preferred. The advantage offered by oversizing lies in a greater security for anchoring the device when it is inserted inside the sewing ring. Furthermore, this choice has proved to be of great use in reducing the risk of paravalvular leakage. However, the risks of extreme oversizing remain to be considered and should be avoided. In fact, a severely under-expanded device can lead to various drawbacks including an increase in the transvalvular gradient, a non-optimal coaptation of the leaflet and a compromised valve durability ${ }^{[1,15]}$. Ultimately, a considerable contribution has been offered by the standardized use of cardiac computed tomography, which has proved to be fundamental in assessing the risk of LVOT obstruction and determining the degree and distribution of 
Table 2. Operative outcomes in transcatheter approach group ${ }^{[1,15,23-26,31]}$

\begin{tabular}{|c|c|c|c|c|c|c|c|c|c|}
\hline & Overall & $\begin{array}{l}\text { Operative } \\
\text { mortality (\%) }\end{array}$ & $\begin{array}{l}\text { Procedural } \\
\text { success (\%) }\end{array}$ & $\begin{array}{l}\text { Major } \\
\text { bleeding } \\
(\%)\end{array}$ & $\begin{array}{l}\text { Reintervention } \\
\text { (\%) }\end{array}$ & $\begin{array}{l}\text { Conversion to } \\
\text { surgery (\%) }\end{array}$ & $\begin{array}{l}\text { LVOT } \\
\text { obstruction }\end{array}$ & $\begin{array}{l}\text { Stroke } \\
(\%)\end{array}$ & $\begin{array}{l}\text { All causes } \\
\text { mortaluty at } 30 \\
\text { days }\end{array}$ \\
\hline US Registry & 349 & & & & & & & & \\
\hline Brigham and Women's Hospital & 520 & $37(7.1)$ & $297.4(57.2)$ & 21 & & $4(0.7)$ & & & \\
\hline TMVR Registry & 248 & $3(1.2)$ & $212(85.5)$ & $24(5.6)$ & $25(10.1)$ & $5(2.0)$ & $8(3.2)$ & $4(1.6)$ & $16(6.5)$ \\
\hline $\begin{array}{l}\text { Mayo Clinic, NY University Medical Centre, } \\
\text { Intermounitain Heart Institute, University of Alabama, St. } \\
\text { Michael's Hospital, Centre Cardiologique du Nord }\end{array}$ & 87 & $5(5)$ & $78(90)$ & $9(10)$ & & $5(6)$ & $8(9)$ & & $5(6)$ \\
\hline Multicentre Published reports (2009-2018) & 245 & $14(5.7)$ & $229(93.5)$ & $15(6.1)$ & & & $4(1.6)$ & $4(1.6)$ & $17(8.1)$ \\
\hline Flinders Medical Centre (Adelaide) (2017-2018) & 7 & $1(14)$ & $6(86)$ & $1(14)$ & & $1(14)$ & & 0 & \\
\hline St. Paul's Hospital (Vancouver, Canada) & 23 & 0 & 100 & $6(26.1)$ & $1(4.4)$ & 0 & & $1(4.4)$ & $2(9.6)$ \\
\hline
\end{tabular}

LVOT: Left ventricular outflow tract; TMVR: transcatheter mitral valve replacement.

calcium deposits in the valvular annulus. The use of CT imaging is useful in guiding the choice of device size in order to oversize by about $5 \%-10 \%$ of the annulus area. In patients with oversizing superior to that 5\%-10\% range, a minimum neo-LVOT area of $250 \mathrm{~mm}^{2}$ and calcification expanding for more than $270^{\circ}(75 \%)$, complications such as valve embolization and LVOT obstruction can be anticipated ${ }^{[14-16,19]}$ [Table 2].

It is important to note that a potential benchmark for the use of TMVT was provided by a Harvard study ${ }^{[1]}$. From 1992 to 2015, at Brigham and Women's Hospital, the authors reported 520 potential candidates for TMViV therapy in whom a failure of previous mitral valve replacement or repair surgery occurred. They had a mean age of $64 \pm 12$ years and a median left ventricular ejection fraction of $60 \%$. Median STS score was $6.12 \% \pm 6.5 \%$. In total, 319 patients had NYHA Class III or IV. Of all patients, 273 had pMVR and 247 had pMVr. There were no differences in term of risk for permanent stroke between the two groups $(5.1 \%$ in pMVR and $5.3 \%$ in pMVr) or necessity of a surgical approach (0.7\% in pMVR and $0.8 \%$ in pMVr), but there was a higher risk of major bleeding in the pMVr group (5.3\%) than in the pMVR group (2.9\%). Operative mortality was higher in the pMVr group (9.3\%) than in the pMVR group (5.1\%).

Recently, this topic has been extensively investigated in the cardiovascular literature. Two recent studies showed different results regarding post-procedural residual mitral stenosis (MS) or residual mitral regurgitation (MR) and analyzed how transcatheter mitral valve replacement (TMVR) can be a valid approach to patients with prosthetic degeneration (TMViV) or ring degeneration (TMViR) or in patients with mitral annulus calcification (TMV-in-MAC) ${ }^{[38-40]}$. 
In one study, 1079 patients from 90 centers were randomized and treated with TMViV $(n=857)$ or TMViR $(n=222)$ therapy. The primary endpoint was patient survival, while secondary endpoints were residual MS (mean gradient $\geq 10 \mathrm{mmHg}$ ), residual $\mathrm{MR}$ (defined as regurgitation $\geq$ moderate) and rate of repeat MV replacement. With a median echocardiographic follow up of 772.5 days, this study found that postprocedural MS was more common in patients treated with TMViV procedure, while post-procedural MR was more common in patients treated with TMViR. This analysis reported that residual MS was correlated with smaller true internal diameter, younger age and larger body mass index, while post-procedural MR was correlated only with TMViR procedure ${ }^{[38]}$.

\section{Surgical therapy: sternotomy or right thoracotomy?}

Reoperative mitral valve (MV) procedures are increasingly common and represent over $10 \%$ of all MV operations in the United States. There is no broad consensus regarding the optimal surgical approach. The decision between a surgical approach via resternotomy or right thoracotomy represents one of the most important steps of the surgical planning ${ }^{[1,24]}$ [Figures 1 and 2].

Anatomical characteristics, concomitant pathologies, risk scores and type of MV degeneration (mitral repair failure or prosthesis degeneration) can be useful for the decision between sternotomy and right thoracotomy. Moreover, recognizing and analyzing the cause and mechanism of primary MV repair failure with reliable intraoperative and predischarge echocardiography is important to improve the outcome of the initial MV repair ${ }^{[23,25]}$ [Figure 3].

Regardless of the type of repair failure/prosthesis degeneration, the presence of peripheral artery disease, high stroke risk, concomitant or previous coronary artery bypass grafting (CABG) or aortic valve surgery represents one of the first parameters that can guide the choice towards the safest surgical approach. Thoracic CT can show anatomical characteristics, such as proximity of right ventricle or pericardium to the sternum or the position of large vessels or graft used for previous CABG, which are useful to identify patients with high or low risk for intraoperative injury in repeat sternotomy [Figure 2].

A publication from the Division of Cardiac Surgery of the University of Maryland School of Medicine in Baltimore ${ }^{[20]}$ shows that repeat sternotomy MV operation can be performed with low perioperative mortality (4.6\%) and low re-entry injury rate (1.5\%) and, moreover, that repeat sternotomy MV operation is not an independent risk factor for operative mortality or morbidity. Furthermore, a recent review of patients who underwent reoperative MV surgery between 2011 and 2017 at four institution within the Northwell Health System confirms that reoperative mitral valve surgery via right anterolateral minithoracotomy, when performed in centers with high experience in minimally invasive surgery, is safe, reproducible and associated with shorter ventilation times, decreased hospital stay and faster postoperative recovery. Furthermore, the type of MV reoperation (re-repair or re-replacement) is not affected by the surgical approach used. These assessments are essential to adopt the safest and most effective surgical approach for the patient's benefit; therefore, we propose a flowchart that can guide the choice of the best surgical approach [Figure 4]. Concomitant tricuspid valve surgery is not important for the decision between sternotomy and right thoracotomy. As shown in a review performed by the Division of Cardiovascular Surgery from Toronto ${ }^{[21]}$, there are several independent predictors of mortality during redo mitral valve replacement: renal failure $(\mathrm{OR}=3.4)$, previous stroke/TIA $(\mathrm{OR}=2.5)$, left ventricle dysfunction $(\mathrm{FE}<40 \%$; $\mathrm{OR}=1.6)$, urgent timing $(\mathrm{OR}=1.5)$ and no subvalvular preservation during first surgery $(\mathrm{OR}=3.4)$. These data show the importance of careful patient selection and meticulous evaluation of the first surgery [Table 3]. 


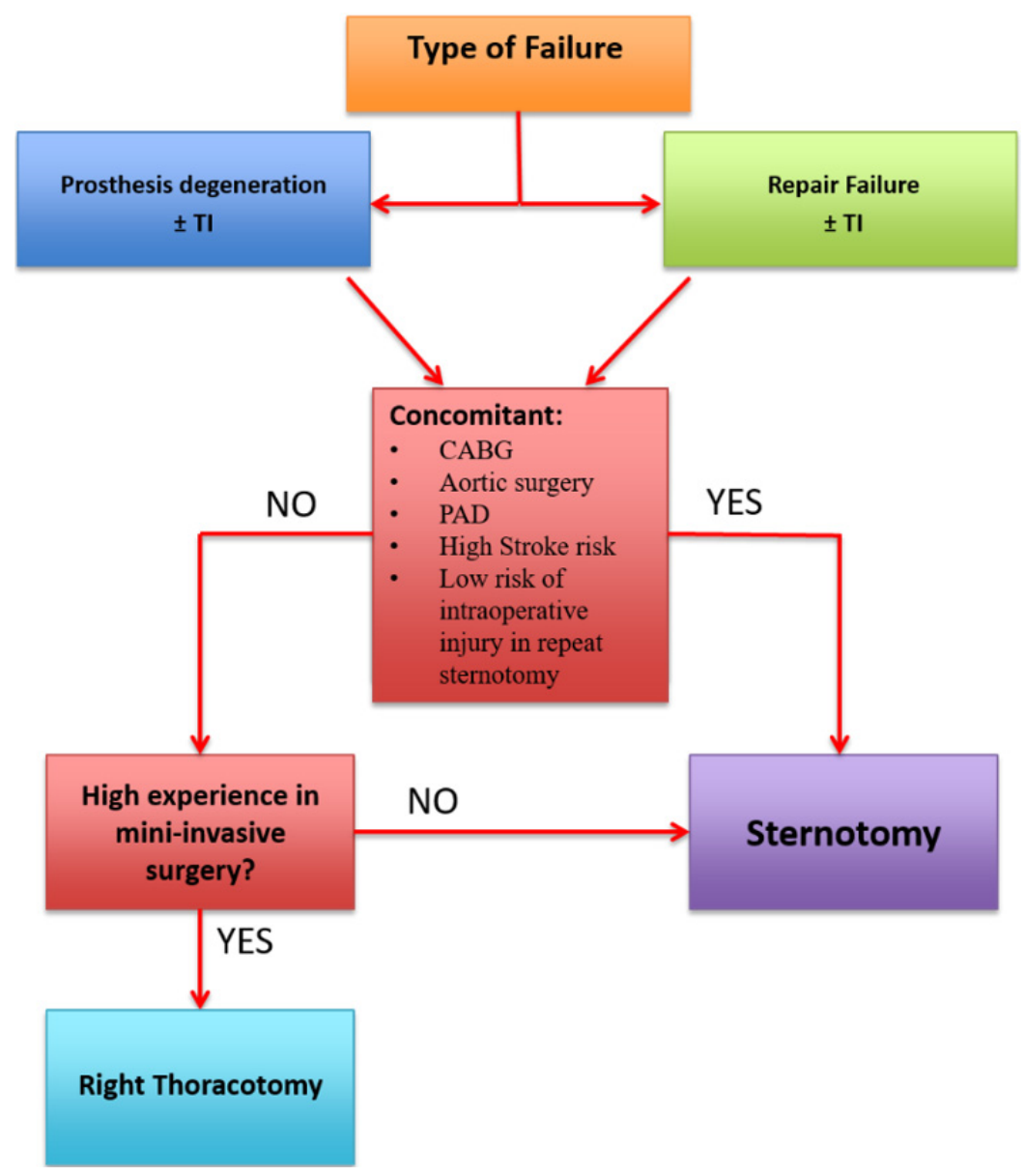

Figure 1. Analysis of the best approach based on the characteristics of the patient and the type of failure of the first surgical approach. CABG: Coronary artery bypass grafting; TI: tricuspid insufficiency; PAD: peripheral artery disease.

Another critical question is: "should the mitral valve be re-repaired or replaced"?

A 2006 retrospective review of patients undergoing surgical correction (repair or replacement) of recurrent MV regurgitation after primary MV repair for regurgitation caused by degenerative valve prolapse analyzed 145 patients who underwent mitral reoperations for recurrent MR at the Mayo Clinic, Rochester ${ }^{[22]}$. This review showed that there were no striking differences, in terms of operative mortality, between the re-repair group and the replacement group, and that three different independent factors were associated with improved survival: MV re-repair, younger age and the preoperative indication of pure MR.

These data emphasize the importance of a prior evaluation of the patient's characteristics and the prior mitral repair failure mechanism for the choice between a re-repair approach, when this is feasible and safe, or replacement. The great advantage of a surgical approach is the possibility to carry out, in young and selected patients, a lasting and probably definitive repair of the mitral valve. Our review shows that there is a better outcome in term of survival at 5 years for patients treated with a re-repair surgery (76\%) compared to patients treated with replacement $(60 \%)$.

The literature recommends that, when the repair failure is correlated to a valvular disease progression, it is advisable to prefer a replacement to avoid a third MV surgery ${ }^{[1,22,25,31]}$ [Table 4]. 


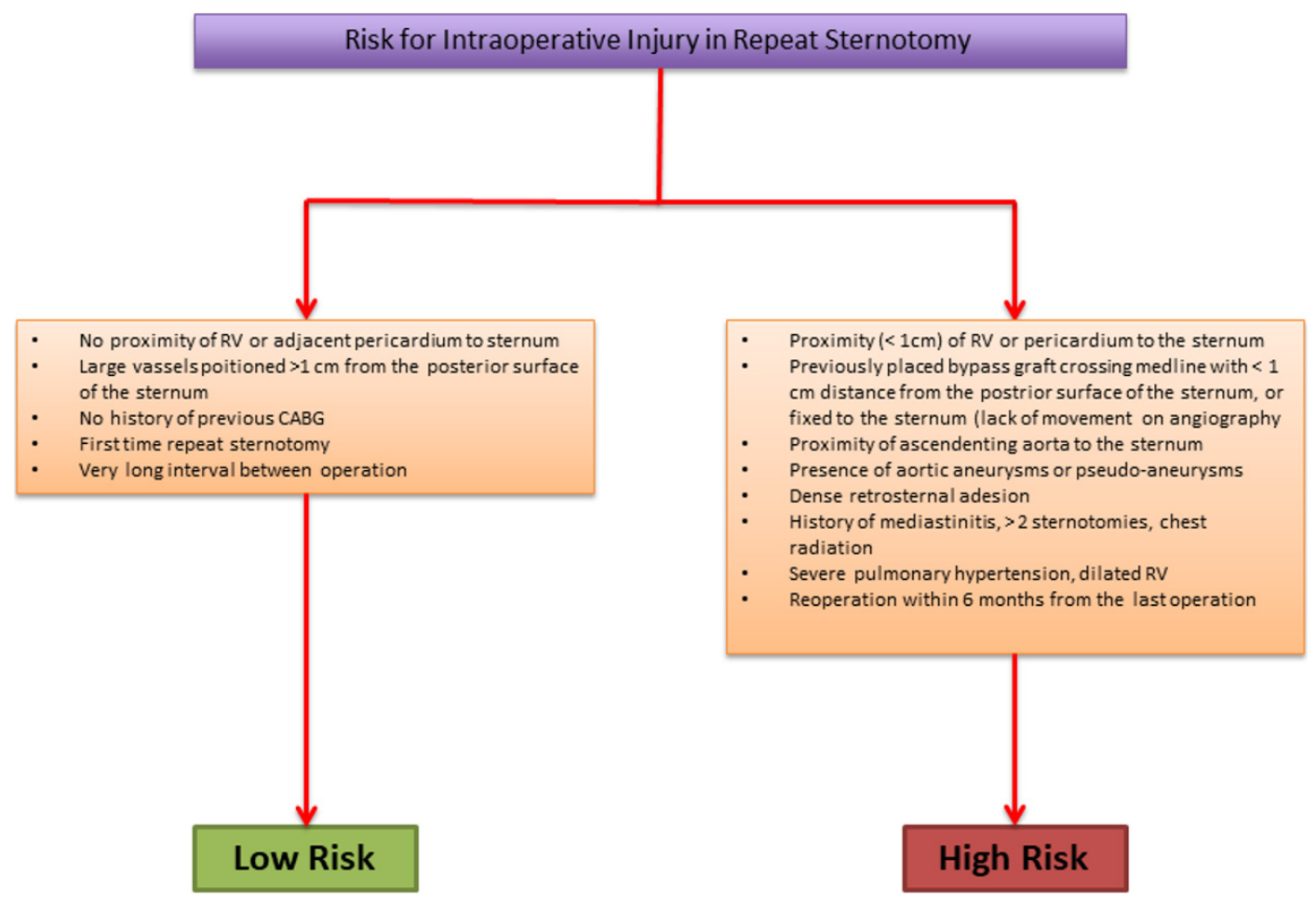

Figure 2. The intraoperative risk factors for a new surgical approach using sternotomy. CABG: Coronary artery bypass grafting; RV: right ventricle.

Aside from the type of surgical approach, we analyze the differences between patients who undergo MV rerepair and MV replacement. We use data from different studies to analyze those differences in terms of operative mortality, stroke risk, major bleeding risk, sternal infection and all causes of mortality at 30 days. A recent review by Patel et al. ${ }^{[21]}$ analyzed the outcomes of 256 patients who underwent reoperative mitral valve surgery from 2011 and 2017. Ninety patients had their redo mitral valve surgery performed via right anterolateral thoracotomy and 166 were approached with a median sternotomy. Thirty-day mortality ( 8 ; $4.4 \%$ vs. $1 ; 1.1 \%)$, stroke $(3 ; 1.8 \%$ vs. $0 ; 0 \%)$, reoperation for bleeding $(5 ; 3.2 \% v$ s. $2 ; 2.2 \%)$, deep wound infection $(4 ; 2.4 \%$ vs. $0 ; 0 \%)$ and sepsis $(6 ; 3.6 \%$ vs. $0 ; 0 \%)$ were higher in the sternotomy group.

The data reported in Tables 2 and 4, when comparing operative mortality, 30-day mortality and procedural success rate, should be analyzed considering the total number of patients treated by reoperation or transvalvular approach. Considering these numbers, it is easy to understand how the fundamental point of the therapeutic choice remains the patient evaluation in order to choose the best operative approach. In well-selected patients, the surgical approach is able to guarantee safe, reproducible and long-lasting results.

\section{DISCUSSION}

Reoperation for deteriorated bioprostheses or failed repair is among the highest risk surgical procedures performed in heart surgery. However, as reported by large surgical series, it is the most effective procedure considering several categories of recipients. Indeed, its efficacy has been demonstrated for patients with moderate to severe prosthetic valve dysfunction, as well as structural and non-structural valve degeneration, such as prosthetic valve dehiscence or endocarditis ${ }^{[2,3,1,45]}$. 


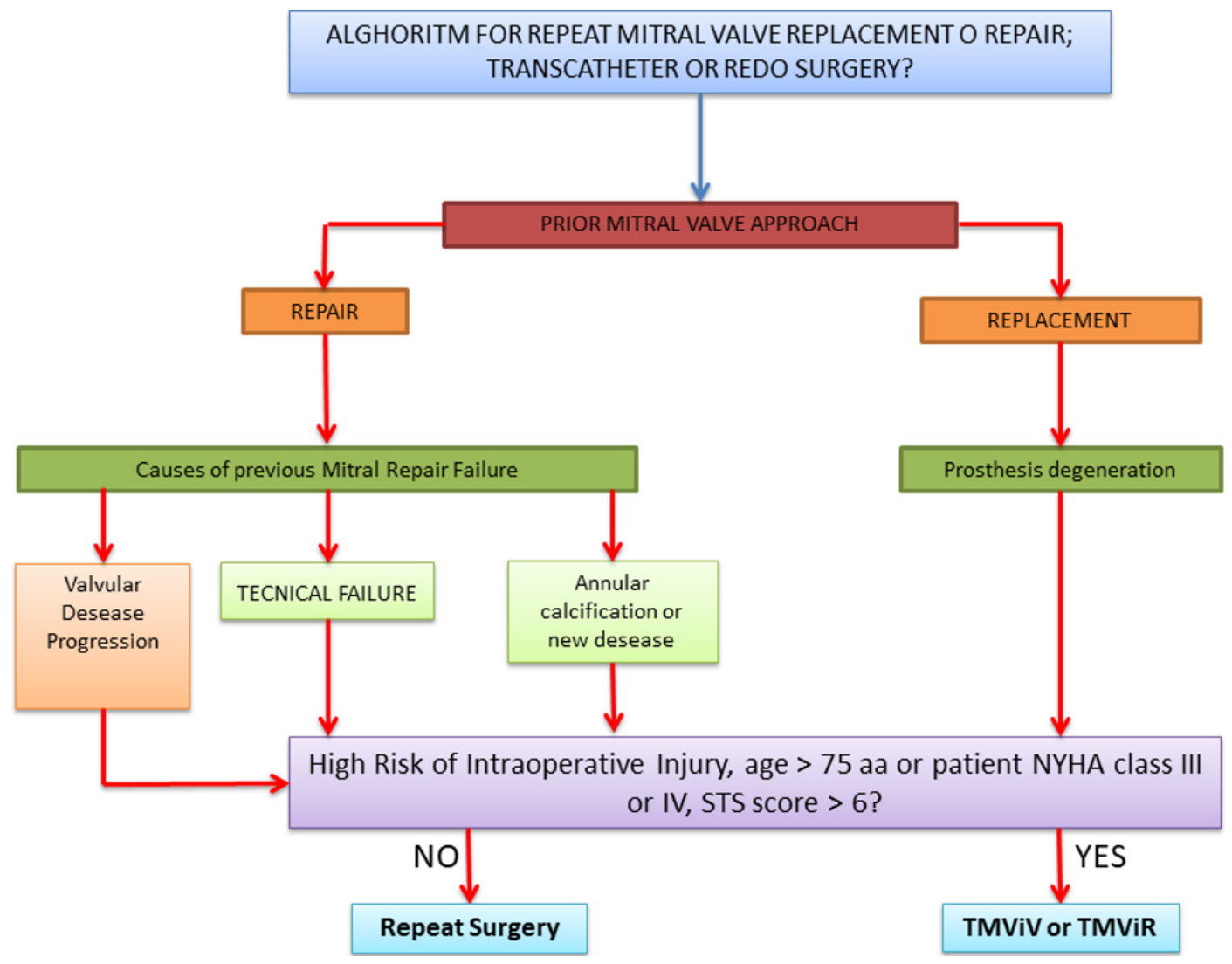

Figure 3. Transcatheter or redo surgery. The choice between a transcatheter approach and a surgical approach cannot preclude the evaluation of the first surgery, the cause of the failure of a previous repair or the presence of a degeneration of mitral valve prosthesis. STS: Society of Thoracic Surgeons; NYHA: New York Heart Association; TMViR: transcatheter mitral valve-in-ring; TMViV: transcatheter mitral valve-in-valve.

Short- and long-term survival is a crucial point for the success of the procedure. However, to date, we do not have precise guidelines that orient the selection of patients who might better benefit from a TMViV-T. Therefore, the choice of the mechanical intervention strategy is not supported by solid scientific evidence.

The literature on the subject has shown that in-hospital mortality rates are substantially lower (between $4 \%$ and $5 \%$ ) for patients who have undergone previous mitral valve repair ${ }^{[16]}$. In contrast, the 30 -day mortality rate was significatively higher for patients who have been managed with conventional Re-MVS for degenerated bioprostheses and ranged from $9.3 \%$ to $12 \%$. Importantly, the pivotal study by Eleid et al. ${ }^{[14]}$ showed a 30-day survival and freedom from secondary cardiac surgery for other complications of $85 \%$ in TMViV and TMViR patients, while this rate was $91 \%$ in a subgroup of TMViV for failed bioprosthetic mitral valve.

The baseline features probably explain the superior intrahospital mortality of the re-mitral valve surgery in the pr-MVRpl group compared to TMViV. The higher operative mortality in patients who received a reoperation for mitral valve replacement was probably related to a proportionately greater number of patients with endocarditis or requiring associated coronary/valve surgery ${ }^{[21-22,44-45]}$. 


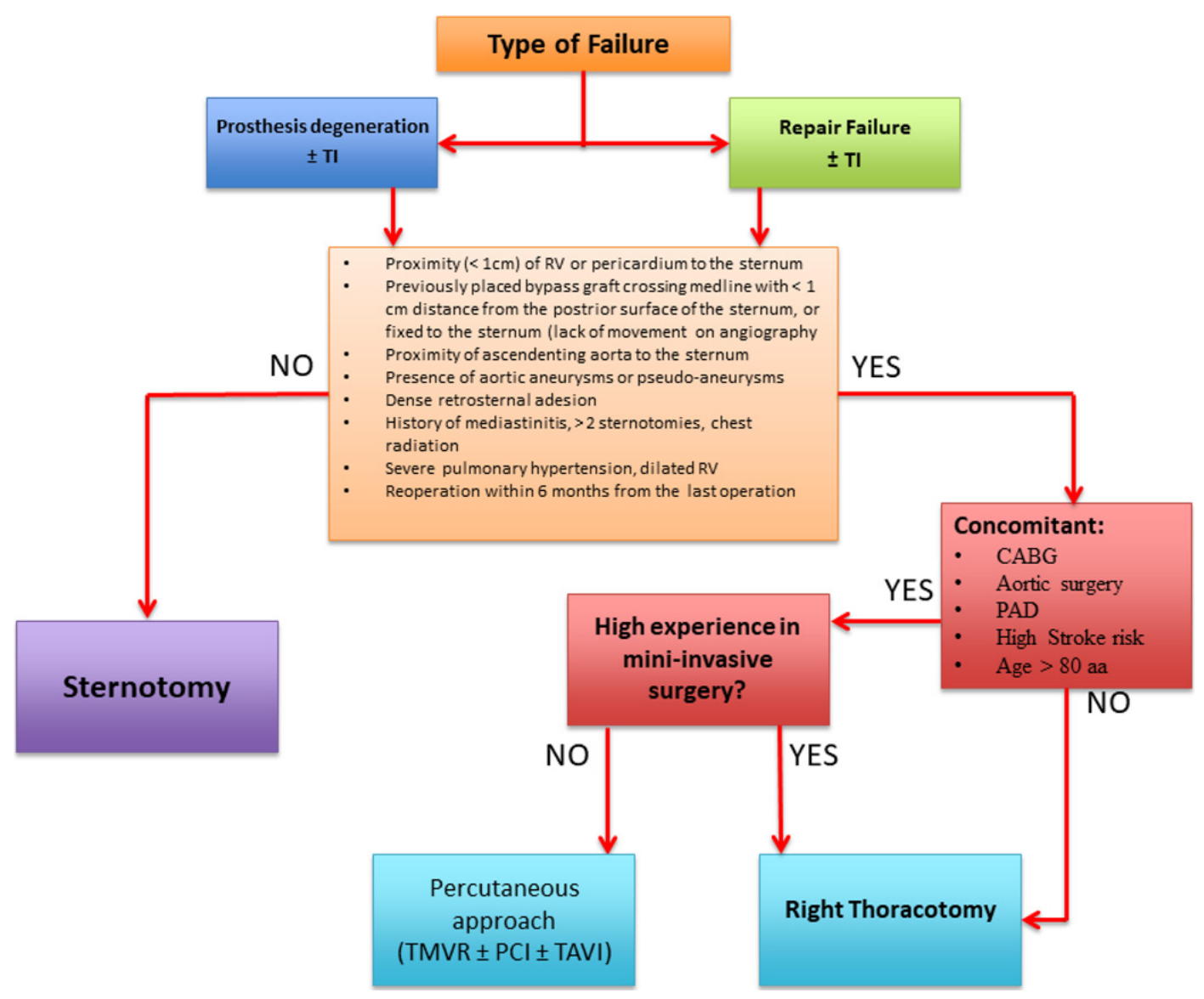

Figure 4. Which approach to use. This flow chart shows how to evaluate which approach would be best and how to choose between a surgical and percutaneous approaches. CABG: Coronary artery bypass grafting; TI: tricuspid insufficiency; RV: right ventricle; PAD: peripheral artery disease, $\mathrm{PCl}$ : percutaneous coronary intervention; TAVI: transcatheter aortic valve implantation; TMVR: transcatheter mitral valve replacement.

Transcatheter heart valve therapy has become technologically advanced with new emerging devices over the past 5 years; however, as stated by the international guidelines and professional societies recommendations, it should be the preferred option only for critically ill patients presenting with symptoms due to isolated MV stenosis or combined regurgitation and stenosis of aortic valve. Candidates for TViV procedure should be discussed by the heart team and considered to be at high or prohibitive risk of reoperation. This recommendation is categorized as Class IIa with a level of evidence B-NR assuming a reasonable improvement in hemodynamics ${ }^{[5,6,15,26]}$.

Currently, the clinical benefits of using TMViV-T are well established by the Mitral Valve Academic Research Consortium (MVARC), which elaborates the consensus document of modern mitral valve surgery. There is no solid evidence to suggest that the use of catheter heart valve therapy is associated with additional benefit in the long-term outcome of patients with degenerated or failed MV. MVARC has also focused on the pathophysiology, prognosis and criteria for the design of clinical trial design in mitral valve disease.

The benefits of TMViV-T apply to high-risk patients, including those with mitral annular calcification, and become evident in the evaluation of primary and secondary genesis of mitral regurgitation. 
Table 3. Baseline characteristics of all patients in surgical approach groups ${ }^{[36-44]}$

\begin{tabular}{|c|c|c|c|c|c|c|c|c|c|c|}
\hline & Overall & Sternotomy & Thoracotomy & $\begin{array}{l}\text { r-MVR } \\
(\%)\end{array}$ & $\begin{array}{l}r-M V r \\
(\%)\end{array}$ & $\begin{array}{l}\text { Age, } y, \\
\text { median }\end{array}$ & $\begin{array}{l}\text { STS } \\
\text { score }\end{array}$ & $\begin{array}{l}\text { NYHA Class III or } \\
\text { IV }\end{array}$ & $\begin{array}{l}\text { LVEF }(\% ; \text { mean } \pm \\
\text { SD) }\end{array}$ & $\begin{array}{l}\text { Heart } \\
\text { failure }\end{array}$ \\
\hline 4 institutions within the Northwell Healt System & 256 & 166 & 90 & $145(56.6)$ & $111(43.4)$ & $62.2 \pm 14.7$ & $8.1 \pm 0.09$ & $93(56)$ & $52.9 \pm 12.6$ & \\
\hline Single Surgical Team (autors ACA and DHA) & 53 & 44 & 9 & $45(84.9)$ & $8(15.1)$ & $57 \pm 13.2$ & & $34(64)$ & $54.3 \pm 10.8$ & \\
\hline $\begin{array}{l}\text { Division of Cardiac Surgery of Maryland School of } \\
\text { Medicine }\end{array}$ & 130 & 130 & 0 & $41(31)$ & $39(30)$ & $62 \pm 15$ & & $96(74)$ & $51 \pm 12$ & \\
\hline Mayo Clinic Rochester & 145 & N.I. & N.I. & $81(56 \%)$ & $64(44)$ & & & $69(47,5)$ & $(n=136)$ & \\
\hline Re-repair & 64 & & & & & $64 \pm 13$ & & & $57 \pm 12$ & \\
\hline Replacement & 81 & & & & & $67 \pm 11$ & & & $56 \pm 11$ & \\
\hline Michigan Medical Centre & 450 & 0 & 450 & & & & & NYHA Class & & \\
\hline Fibrillatory Arrest & 134 & 0 & 134 & $55(41.1)$ & $79(58.9)$ & $63 \pm 13$ & & $2.7 \pm 0.8$ & $36 \pm 13$ & \\
\hline Beating heart & 316 & 0 & 316 & $101(33)$ & $215(67)$ & $63 \pm 15$ & & $2.6 \pm 0.7$ & $38 \pm 9$ & \\
\hline Pennsylvania Health System & 305 & 249 & 56 & 257 & 48 & & & & LVEF $<\mathbf{4 0 \%}(\%)$ & \\
\hline Re-repair & & & & & & $61 \pm 16$ & & N.I. & $10(19)$ & \\
\hline Replacement & & & & & & $62 \pm 15$ & & N.I. & $38(15)$ & \\
\hline Medicare Provider Analysis and Review & 1627 & & & 815 & 812 & 74 & & & & 1275 \\
\hline Re-repair & 285 & & & & & & & & & \\
\hline Replacement & 1332 & & & & & & & & & \\
\hline A 10-year single-centre experience & 49 & & & 49 & & $63 \pm 13$ & & & & \\
\hline $\begin{array}{l}\text { Division of Cardiovascular Surgery, Toronto General } \\
\text { Hospital }\end{array}$ & 513 & & & & & $57 \pm 13$ & & $227(44)$ & $<40 \%(15 \%)$ & \\
\hline
\end{tabular}

STS: Society of Thoracic Surgeons; NYHA: New York Heart Association; LVEF: left ventricle ejection fraction; r-MVR: redo mitral valve replacement; r-MVr: redo mitral valve repair; N.I.: not indicated.

Regarding TMViV-T, the following is fundamental. First, the evaluation of clinically relevant endpoints should reflect the safety and efficacy of MRI treatments. Second, consistent clinical definitions for these endpoints should be used across the relevant studies. The use of TMViV-T as mechanical intervention is aimed to change the extent of the survival benefit. In contrast, the evidence on the use of a standard surgical approach has consistently shown favorable results, and this option has gained the support of the surgical community. 
Table 4. Operative outcomes in surgical approach groups ${ }^{[5,31,36-43]}$

\begin{tabular}{|c|c|c|c|c|c|c|c|}
\hline & Overall & $\begin{array}{l}\text { Operative mortality } \\
(\%)\end{array}$ & $\begin{array}{l}\text { Procedural success } \\
(\%)\end{array}$ & $\begin{array}{l}\text { Major bleeding } \\
(\%)\end{array}$ & $\begin{array}{l}\text { Sternal infection or } \\
\text { sepsi }\end{array}$ & $\begin{array}{l}\text { Stroke } \\
(\%)\end{array}$ & $\begin{array}{l}\text { All causes mortaluty at } 30 \\
\text { days }\end{array}$ \\
\hline 4 institutions within the Northwell Healt System & 256 & 0 & $201(78.5)$ & $7(2.73)$ & $10(3.9)$ & $3(1.17)$ & $9(3.5)$ \\
\hline Single Surgical Team (autors ACA and DHA) & 53 & 0 & 53 & N.I. & N.I. & N.I. & 0 \\
\hline $\begin{array}{l}\text { Division of Cardiac Surgery of Maryland School of } \\
\text { Medicine }\end{array}$ & 130 & $6(4.6)$ & $96(73.8)$ & $5(4)$ & $2(1.5)$ & $3(2.2)$ & N.I. \\
\hline Mayo Clinic Rochester & 145 & & $113.1(78)$ & & & & \\
\hline Re-repair & 64 & $1.02(1.6)$ & & & & & \\
\hline Replacement & 81 & $3.9(4.9)$ & & & & & \\
\hline Michigan Medical Centre & 450 & & & & & & \\
\hline Fibrillatory Arrest & 134 & 0 & N.I. & 2 & $4(3)$ & $4(2.9)$ & $10(7.4)$ \\
\hline Beating heart & 316 & 1 & N.I. & 2 & $8(2.6)$ & $7(2.21)$ & $22(6.9)$ \\
\hline Pennsylvania Health System & 305 & & & & & & \\
\hline Re-repair & 48 & 0 & $40(83.3)$ & 0 & $2(4.16)$ & 0 & N.I. \\
\hline Replacement & 257 & $21(8)$ & $130(50.5)$ & $15(6)$ & $14(5)$ & $9(4)$ & N.I. \\
\hline Medicare Provider Analysis and Review & 1627 & $205(12.6)$ & & & & & $195.24(12)$ \\
\hline Re-repair & 285 & & & & & & \\
\hline Replacement & 1332 & & & & & & \\
\hline A 10-year single-centre experience & 49 & $6(12)$ & $2(4.08)$ & $2(4)$ & & $4(8)$ & $20(40.8)$ \\
\hline $\begin{array}{l}\text { Division of Cardiovascular Surgery, Toronto General } \\
\text { Hospital }\end{array}$ & 513 & 46.17 (9) & & & & & \\
\hline
\end{tabular}

N.I.: Not indicated.

A contemporary analysis of the STS Adult Cardiac Surgery Database revealed that, in the United States during 2015, a little over 2\% of patients underwent a TMViV-T compared to a total of 12,792 surgical procedure of mitral valve repairs and 4548 interventions of mitral valve replacements ${ }^{[8,25,30,34]}$

Between $4 \%$ and $10 \%$ of patients comprised who are managed with a mitral valve repair will require a second operation and usually the reoperation is a mitral valve replacement. The rationale for this reduced use of re-repair is complex and multifactorial. 
A survey reported in a French study and published more than three decades ago found a greater use of mitral valve re-repairs than replacement. However, several other studies showed that the percentage of patients in whom repair was feasible ranged $36 \%-85 \%$.

Repeat open mitral valve replacement is preferred in patients who require a second operation for endocarditis, mitral stenosis, bileaflet prolapse or severe degenerative progression of native disease $\mathrm{e}^{[8,29,30,32]}$.

In this scenario, short-term quality metrics can be determining factors in influencing surgical decisionmaking because they directly affect the financial situation of the institutions and the employer/health provider relationship. For example, these metrics have driven the choice for patients who received mitral valve replacement surgery with bioprosthetic valves being preferred for the avoidance of anticoagulant therapy and despite the risk of structural deterioration.

It is important to note that to date the expense for the treatment of thrombotic complications after standard surgery mechanical prostheses is "not negligible", as evidenced by the United States Center for Medicare \& Medicaid Services.

Nevertheless, a study from Harvard reporting the 24-year experience of 520 patients who were reoperated after preceding MV replacement or MV repair showed that the use of a repeat mitral valve replacement increased operative mortality $(7.1 \%)$ or other major morbidity $(18.2 \%)$. Moreover, the use of the mitral valve repair, instead of the replacement, revealed a higher long-term survival, as noted with a Cox-adjusted analysis.

It is clear that repeat mitral valve replacement is burdened by higher mortality, as shown by Suri et al. ${ }^{[22]}$, Anyanwu et al..$^{[44]}$, David et al. ${ }^{[46]}(6.9 \%)$, Borger et al. ${ }^{[36]}$ (9\%) and Vohra et al. ${ }^{[5]}$ (12\%), at over 10-year follow-up. Concerns related to the survival benefit at 30 days are due to: (1) largely increased technical problem relative to reintervention; (2) increased frailty of patients undergoing reoperation; and (3) the fact that prosthetic valve endocarditis is a usual indication for repeat surgery. In this group, the slightly superior operative mortality and inferior long-term survival in patients who received a homograft may affect the long-term results.

The evidence produced previously indicates that contemporary mitral valve redo surgery should involve both the use of the standard approach and TMViV/R therapy - the latter in the absence of clinical or anatomic contraindications - and substantial efforts should be made to raise the promotion of TMViV/R therapy using transfemoral/transatrial approach in inoperable/high risk patients.

The increasing use of bioprostheses even in young patients has changed the platform for mitral valve interventions and TMViV/TMViR could be considered similar alternatives in patients with degenerated mitral and ring bioprostheses or MAC. However, concerns remain over the widespread use of TMViV/R because of the lack of solid evidence on the durability of these devices implanted in the mitral position as well as the potential risk of LVOT obstruction. Early outcomes of TMVR indicate that the procedure should be preferred in high-risk cases because it has low periprocedural mortality. In addition, the occurrence of early complications such as embolization, frequent paravalvular leaks with either C- or D-shaped rings and obstruction of the left ventricular outflow tract due to malposition of the device must be taken into account. 
Recently, Yoon et al. ${ }^{[24]}$ showed superior midterm outcomes in patients who received TMViV $(n=176)$ compared to those who underwent TMViR $(n=72)$. The authors noted that patients receiving the mitral valve transcatheter procedure for failure of a ring annuloplasty had higher rates of procedural complications compared to those who had mitral valve in the valve for failure of degenerated bioprostheses valve with a technical success of $83.3 \%$ vs. $96 \%(P=0.001)$, respectively. Medium-term (1-year) mortality was also higher in the TMViR group $(28.7 \%$ vs. $12.6 \% ; P=0.01)$. Additionally, mechanical intervention for failed annuloplasty showed worse outcomes in patients who received TMViR and was independently associated with all-cause mortality, as noted with multivariate Cox analysis ( $\mathrm{HR}=2.7 ; 95 \% \mathrm{CI}: 1.34-5.43 ; P=0.005)$.

The FDA approved the use TMVR in prohibitive/high-risk patients but comparable data for surgical repeat mitral valve repair or replacement outcomes are also needed to assess its safety and indications, especially in lower-risk patients. TMViR was shown to have poorer results compared to TMViV or MV surgery.

TMViR or valve in MAC is probably less competitive in specific anatomic configuration and less appropriate in cases of severe hypertrophic obstructive cardiomyopathy for the higher risk of anterior mitral leaflet displacement. Post-mitral TMViV/R alcohol septal ablation and good prosthetic valve function cannot be considered helpful to improve the efficacy of the procedure in cases of critical obstruction because paravalvular leakage is common.

The use of the future benchmarking to TMViV/R could be limited for the presence of young patients, in whom the procedure is not indicated for ethical and clinical reasons. Resistance to the use of TMViV/R among surgeons and cardiologists can be motivated, at least in part, by the fact that the clinical advantage of $\mathrm{TMViV} / \mathrm{R}$ therapy has only been shown in observational reports and has never been confirmed in randomized clinical studies.

The ongoing RCT Mitral Implantation of Transcatheter Valves trial (NCT02370511) can certainly provide further clarifications; however, no patients have been enrolled for a surgical repeat mitral valve replacement in this registry.

Data from the literature are unable to reach meaningful conclusions, so more in-depth investigations are required.

\section{CONCLUSION}

This review analyzes different outcomes between percutaneous and surgery approaches for degenerated or failed previous mitral valve intervention.

Data extracted from different studies and reviews help us establish a valid protocol of choice for patients who need redo surgery due to the degeneration of a mitral biological valve prosthesis or a previous failed mitral valve repair. The choice between the two methods of reintervention involves the analysis of different factors and, as described above, is the result of a careful evaluation of the patient characteristics and comorbidities, the presence of concomitant aortic valve pathology or coronary artery disease, the type of previous surgery approach and life expectancy. Recently, different studies have shown, in agreement with our results, that both procedures, TMViV and TMViR, can present different degrees of residual insufficiency or residual valve stenosis. According to these results, the only way to guarantee the best clinical result is the careful choice of the patient to be a candidate for TMViV/ViR or for reoperation ${ }^{[38-40]}$. 
To begin, it is necessary to evaluate what was the initial mitral valve approach during the primary surgery. In the case of repair, we should analyze why the repair failed and if a new repair could be lasting and safe. We should prefer a replacement performed by surgery or a percutaneous approach if this is not possible. In this scenario, patient age, previous CABG or aortic surgery, or concomitant necessity of CABG or aortic surgery, can help us in our choice. In older patients ( $>80$ years old) with no concomitant necessity of CABG or aortic surgery, TMViV or TMViR intervention could be the indicated approach with a lower operation mortality risk and a better long-term outcome. Conversely, in young patients, without comorbidities and regardless of the concomitant need for CABG or aortic surgery, with a high probability of success of a new surgical repair/replacement of the valve, a surgical approach, by resternotomy or via right thoracotomy, is recommended, because of the increased chances of a long-lasting result.

As shown in our results. there are no striking differences in terms of operative or long-term mortality between surgery and percutaneous reintervention in well selected patients. An important emphasis should be given to tailor the most suitable, safe and effective approach for the correct patient.

\section{DECLARATIONS}

\section{Authors' contributions}

Study design: Nappi F, Verghi E, Chello M

Data acquisition: Nappi F, Verghi E, Avtaar Singh SS, Nenna A, Nappi P

Data interpretation: Nappi F, Verghi E, Nappi P

Manuscript drafting: Nappi F, Verghi E, Avtaar Singh SS, A Nenna

Revision of the manuscript: Nappi F, Chello C, Chello M

\section{Availability of data and materials}

Not applicable.

\section{Financial support and sponsorship}

None.

\section{Conflict of interest}

All authors declared that there are no conflicts of interest.

\section{Ethical approval and consent to participate}

Not applicable.

\section{Consent for publication}

Not applicable.

\section{Copyright}

(C) The Author(s) 2021.

\section{REFERENCES}

1. Ejiofor JI, Hirji SA, Ramirez-Del Val F, et al. Outcomes of repeat mitral valve replacement in patients with prior mitral surgery: A benchmark for transcatheter approaches. J Thorac Cardiovasc Surg 2018;156:619-27.e1. DOI PubMed

2. Nappi F, Antoniou GA, Nenna A, et al. Treatment options for ischemic mitral regurgitation: A meta-analysis. $J$ Thorac Cardiovasc Surg ;2020:S0022-5223(20)31262. DOI PubMed

3. Nappi F, Nenna A, Sing SSA, et al. Mitral regurgitation: lessons learned from COAPT and MITRA-Fr. J Thorac Dis 2020;12:2936-44. DOI PubMed PMC

4. Nappi F, Nenna A, Timofeeva I, Mihos C, Gentile F, Chello M. Mitral regurgitation after transcatheter aortic valve replacement. $J$ Thorac Dis 2020;12:2926-35. DOI PubMed PMC

5. Vohra HA, Whistance RN, Roubelakis A, et al. Outcome after redo-mitral valve replacement in adult patients: a 10-year single-centre 
experience. Interact Cardiovasc Thorac Surg 2012;14:575-9. DOI PubMed PMC

6. Bourguignon T, Bouquiaux-Stablo AL, Loardi C, et al. Very late outcomes for mitral valve replacement with the Carpentier-Edwards pericardial bioprosthesis: 25-year follow-up of 450 implantations. J Thorac Cardiovasc Surg 2014;148:2004-11.e1. DOI PubMed

7. Condado JF, Kaebnick B, Babaliaros V. Transcatheter mitral valve-in-valve therapy. Interv Cardiol Clin 2016;5:117-23. DOI PubMed

8. Nappi F, Avtaar Singh SS, Padala M, et al. The choice of treatment in ischemic mitral regurgitation with reduced left ventricular function. Ann Thorac Surg 2019;108:1901-12. DOI PubMed PMC

9. Nappi F, Lusini M, Avtaar Singh SS, Santana O, Chello M, Mihos CG. Risk of ischemic mitral regurgitation recurrence after combined valvular and subvalvular repair. Ann Thorac Surg 2019;108:536-43. DOI PubMed

10. Elmariah S, Arzamendi D, Llanos A, et al. First experience with transcatheter valve-in-valve implantation for a stenotic mitral prosthesis within the United States. JACC Cardiovasc Interv 2012;5:e13-4. DOI PubMed

11. Coylewright M, Cabalka AK, Malouf JA, et al. Percutaneous mitral valve replacement using a transvenous, transseptal approach: transvenous mitral valve replacement. JACC Cardiovasc Interv 2015;8:850-7. DOI PubMed

12. Nappi F, Spadaccio C, Sablayrolles JL. Pushing the limits in transcatheter aortic valve replacement: High-volume center's effect, overconfidence, or something else? JACC Cardiovasc Interv 2016;9:2186-8. DOI PubMed

13. Sorajja P, Mack M, Vemulapalli S, et al. Initial experience with commercial transcatheter mitral valve repair in the United States. $J$ Am Coll Cardiol 2016;67:1129-40. DOI PubMed

14. Eleid MF, Cabalka AK, Williams MR, et al. Percutaneous transvenous transseptal transcatheter valve implantation in failed bioprosthetic mitral valves, ring annuloplasty, and severe mitral annular calcification. JACC Cardiovasc Interv 2016;9:1161-74. DOI PubMed

15. Eleid MF, Whisenant BK, Cabalka AK, et al. Early outcomes of percutaneous transvenous transseptal transcatheter valve implantation in failed bioprosthetic mitral valves, ring annuloplasty, and severe mitral annular calcification. JACC Cardiovasc Interv 2017;10:193242. DOI PubMed

16. Attias D, Nejjari M, Nappi F, Dreyfus J, Eleid MF, Rihal CS. How to treat severe symptomatic structural valve deterioration of aortic surgical bioprosthesis: transcatheter valve-in-valve implantation or redo valve surgery? Eur J Cardiothorac Surg 2018;54:977-85. DOI PubMed

17. Rumsfeld JS, Holmes DR Jr, Stough WG, Edwards FH, Jacques LB, Mack MJ. Insights from the early experience of the Society of Thoracic Surgeons/American College of Cardiology Transcatheter Valve Therapy Registry. JACC Cardiovasc Interv 2015;8:377-81. DOI PubMed

18. Carroll JD, Edwards FH, Marinac-Dabic D, et al. The STS-ACC transcatheter valve therapy national registry: a new partnership and infrastructure for the introduction and surveillance of medical devices and therapies. J Am Coll Cardiol 2013;62:1026-34. DOI PubMed

19. Feldman T, Kar S, Elmariah S, et al; EVEREST II Investigators. Randomized comparison of percutaneous repair and surgery for mitral regurgitation: 5-year results of EVEREST II. J Am Coll Cardiol 2015;66:2844-54. DOI PubMed

20. Ghoreishi M, Dawood M, Hobbs G, et al. Repeat sternotomy: no longer a risk factor in mitral valve surgical procedures. Ann Thorac Surg 2013;96:1358-65. DOI PubMed

21. Patel NC, Hemli JM, Seetharam K, et al. Reoperative mitral valve surgery via sternotomy or right thoracotomy: A propensity-matched analysis. J Card Surg 2019;34:976-82. DOI PubMed

22. Suri RM, Schaff HV, Dearani JA, et al. Recurrent mitral regurgitation after repair: should the mitral valve be re-repaired? J Thorac Cardiovasc Surg 2006;132:1390-7. DOI PubMed

23. Hu J, Chen Y, Cheng S, et al. Transcatheter mitral valve implantation for degenerated mitral bioprostheses or failed surgical annuloplasty rings: A systematic review and meta-analysis. J Card Surg 2018;33:508-19. DOI PubMed PMC

24. Yoon SH, Whisenant BK, Bleiziffer S, et al. Transcatheter mitral valve replacement for degenerated bioprosthetic valves and failed annuloplasty rings. J Am Coll Cardiol 2017;70:1121-31. DOI PubMed

25. Nishida H, Fukui T, Kasegawa H, Kin H, Yamazaki M, Takanashi S. Causes of repair failure for degenerative mitral valve disease and reoperation outcomes. Eur J Cardiothorac Surg 2018;53:1244-50. DOI PubMed

26. Grover FL, Vemulapalli S, Carroll JD, et al; STS/ACC TVT Registry. 2016 Annual Report of The Society of Thoracic Surgeons/American College of Cardiology Transcatheter Valve Therapy Registry. J Am Coll Cardiol 2017;69:1215-30. DOI PubMed

27. Stone GW, Lindenfeld J, Abraham WT, et al; COAPT Investigators. Transcatheter mitral-valve repair in patients with heart failure. $N$ Engl J Med 2018;379:2307-18. DOI PubMed

28. Obadia JF, Messika-Zeitoun D, Leurent G, et al; MITRA-FR Investigators. Percutaneous repair or medical treatment for secondary mitral regurgitation. N Engl J Med 2018;379:2297-306. DOI PubMed

29. Nappi F. The use of subvalvular repair for functional mitral regurgitation. Ann Thorac Cardiovasc Surg 2020. DOI PubMed

30. Nappi F, Avatar Singh SS, Santana O, Mihos CG. Functional mitral regurgitation: an overview for surgical management framework. $J$ Thorac Dis 2018;10:4540-55. DOI PubMed PMC

31. Cheung A, Webb JG, Barbanti M, et al. 5-year experience with transcatheter transapical mitral valve-in-valve implantation for bioprosthetic valve dysfunction. J Am Coll Cardiol 2013;61:1759-66. DOI PubMed

32. Nappi F, Spadaccio C, Chello M, Lusini M, Acar C. Double row of overlapping sutures for downsizing annuloplasty decreases the risk of residual regurgitation in ischaemic mitral valve repair. Eur J Cardiothorac Surg 2016;49:1182-7. DOI PubMed

33. Webb JG, Wood DA, Ye J, et al. Transcatheter valve-in-valve implantation for failed bioprosthetic heart valves. Circulation 2010;121:1848-57. DOI PubMed 
34. Descoutures F, Himbert D, Maisano F, et al. Transcatheter valve-in-ring implantation after failure of surgical mitral repair. Eur J Cardiothorac Surg 2013;44:e8-15. DOI PubMed

35. Seiffert M, Conradi L, Baldus S, et al. Transcatheter mitral valve-in-valve implantation in patients with degenerated bioprostheses. JACC Cardiovasc Interv 2012;5:341-9. DOI PubMed

36. Borger MA, Yau TM, Rao V, Scully HE, David TE. Reoperative mitral valve replacement: importance of preservation of the subvalvular apparatus. Ann Thorac Surg 2002;74:1482-7. DOI PubMed

37. Gammie JS, Sheng S, Griffith BP, et al. Trends in mitral valve surgery in the United States: results from the Society of Thoracic Surgeons Adult Cardiac Surgery Database. Ann Thorac Surg 2009;87:1431-7; discussion 1437. DOI PubMed

38. Simonato M, Whisenant B, Ribeiro HB, et al. Transcatheter mitral valve replacement after surgical repair or replacement: Comprehensive midterm evaluation of valve-in-valve and valve-in-ring implantation from the VIVID registry. Circulation 2021;143:104-16. DOI PubMed

39. Bapat VN. Mitral valve-in-valve, valve-in-ring, and valve-in-mitral annular calcification: Are we there yet? Circulation 2021;143:1179. DOI PubMed

40. Urena M, Vahanian A, Brochet E, Ducrocq G, Iung B, Himbert D. Current indications for transcatheter mitral valve replacement using transcatheter aortic valves: Valve-in-valve, valve-in-ring, and valve-in-mitral annulus calcification. Circulation 2021;143:178-96. DOI PubMed

41. Kwedar K, McNeely C, Zajarias A, Markwell S, Vassileva CM. Outcomes of early mitral valve reoperation in the medicare population. Ann Thorac Surg 2017;104:1516-21. DOI PubMed

42. Kilic A, Helmers MR, Han JJ, et al. Redo mitral valve surgery following prior mitral valve repair. J Card Surg 2018;33:772-7. DOI PubMed

43. Romano MA, Haft JW, Pagani FD, Bolling SF. Beating heart surgery via right thoracotomy for reoperative mitral valve surgery: a safe and effective operative alternative. J Thorac Cardiovasc Surg 2012;114:334-9. DOI PubMed

44. Anyanwu AC, Itagaki S, Varghese R, Castillo J, Chikwe J, Adams DH. Re-repair of the mitral valve as a primary strategy for early and late failures of mitral valve repair. Eur J Cardiothorac Surg 2014;45:352-7; discussion 357. DOI PubMed

45. LaPar DJ, Ailawadi G, Isbell JM, et al; Virginia Cardiac Surgery Quality Initiative. Mitral valve repair rates correlate with surgeon and institutional experience. J Thorac Cardiovasc Surg 2014;148:995-1003; discussion 1003. DOI PubMed

46. David TE, Armstrong S, McCrindle BW, Manlhiot C. Late outcomes of mitral valve repair for mitral regurgitation due to degenerative disease. Circulation 2013;127:1485-92. DOI PubMed 